\title{
ANÁlise do CULTIVO DE CAFÉ EM ESPERA FELIZ (MG) EM MEADOS DO SÉCULO XX
}

\author{
ANALYSIS OF COFFEE CULTIVATION IN ESPERA FELIZ (MG) IN MID 20TH \\ CENTURY
}
Leandra de Oliveira Ferreira ${ }^{1}$, Wesley Henrique Gonçalves ${ }^{2}$ e Wagner dos Reis Marques Araújo ${ }^{3}$

1 Universidade do Estado de Minas Gerais, Graduada em História, Brasil, e-mail: leandraoliveira05@outlook.com

2 Universidade do Estado de Minas Gerais, Graduado em História, e-mail: wesleyhenrique1055@gmail.com de Minas Gerais, Doutor em Sociologia, Brasil, e-mail: wagner.araujo@uemg.br

A R T I C L E I N F O
Article history:
Received 2020-02-10
Accepted 2020-02-20
Available online 2020-02-20

RESUMO. O presente artigo é resultado de uma pesquisa sobre o desenvolvimento da produção agrícola em Espera Feliz, MG, por volta de meados do século XX, cujo objetivo principal do estudo consistiu identificar as características agrícolas e os principais produtos cultivados na região, pensados como resultado específico de um processo histórico de ocupação e uso do solo na Zona da Mata Mineira. A pesquisa partiu da análise de dados estatísticos referentes à produção agrícola desse município para caracterizar como ocorreu o desenvolvimento socioeconômico do munícipio com base na agricultura, identificando a sua vocação para determinado setor agrícola. Os dados quantitativos foram confrontados com referenciais teóricos-metododologicos que discutem sobre a História Agrária. A pesquisa concluiu que a economia de Espera Feliz partiu do cultivo do café como produto de exportação, influenciando o crescimento socioeconômico local, projetando o município como uma rica região produtora de cafés especiais.

ABSTRACT. This article is the result of a research on the development of agricultural production in Espera Feliz, MG, around the middle of the 20th century, whose main objective of the study was to identify the agricultural characteristics and the main products grown in the region, designed as a specific result of a historical process of land occupation and use in the Zona da Mata Mineira. The research started from the analysis of statistical data referring to the agricultural production of this municipality to characterize how the socioeconomic development of the municipality based on agriculture occurred, identifying its vocation for a certain agricultural sector. The quantitative data ones were compared with theoretical-methodological references that discuss Agrarian History. The research concluded that the Espera Feliz economy started from the cultivation of coffee as an export product, influencing the local socioeconomic growth, projecting the municipality as a rich producer of specialty coffees.

\section{Introdução}

Neste texto apresenta-se os resultados de um estudo que visou mapear o desenvolvimento da produção agrícola em Espera Feliz por volta de meados do século XX. Esse município está localizado na sub-região Norte da Zona da Mata Mineira, que está 
situada na confluência entre os estados de Minas Gerais (MG), Rio de Janeiro (RJ) e Espírito Santo (ES). Intentou-se identificar as características agrícolas e os principais produtos cultivados na região, pensados como resultado específico de um processo histórico de ocupação e uso do solo. Partiu-se da seguinte problemática de pesquisa: que modalidade de agricultura sustentou no século passado a economia de Espera Feliz? Quais fatores contribuíram para o desenvolvimento da produção agrícola local, com destaque para determinados tipos de cultura?

A pesquisa partiu da análise de dados estatísticos referentes à produção agrícola de Espera Feliz, especificamente a partir de meados do século XX, pontuando como ocorreu o desenvolvimento econômico do munícipio com base na agricultura e identificando a sua vocação para determinado setor produtivo. Para tanto, foi necessário analisar dados quatitativos disponíveis no site do Instituto Brasileiro de Geografia e Estatística - IBGE, referentes à produção agrícola desse município para o período analisado, e confrontá-los com referenciais teóricos-metododologicos que versam sobre o tema.

À vista disso, foi realizada uma análise descritiva dos dados uma vez que o estudo utilizou a análise de dados quantitativos e qualitativos, ou seja, foi necessário realizar um levantamento de dados e apontar o porquê desses para comprovação dos fatos por meio de uma análise de conteúdo (BOENTE e BRAGA, 2004). A exploração técnica consiste no primeiro passo de uma pesquisa que deve ser sistemática e exata, onde o pesquisador utiliza como base estudos já realizados por outros teóricos (MARCONI e LAKATOS 2002).

Os estudos de Linhares (2011) e Carrara (1999) foram ulilizados como referencial teórico-metodológico por terem como principal área de pesquisas a "história agrária". Inicialmente foi verificado que a produção cafeeira de Espera Feliz apresenta elevado nível produtivo e de qualidade nessa região, conforme indicam os dados do IBGE (2018).

O recorte temporal escolhido foi meados do século $X X$ que se justifica devido as análises da fontes bibliográficas que aponta esse período como relevante na produção agrícola de Espera Feliz, por exemplo, o Censo Agrícola de 1949-1950 do IBGE. A partir de tais dados foi possível realizar o mapeamento da produção agrícola do município, constatando-se que as culturas de café, cebola, batata, feijão e milho já predominavam em meados do século XX. Com base nesses dados, analisou-se a importância de tais produtos como fonte econômica de Espera Feliz, porém, constatando-se a predominância da produção cafeeira.

\section{A compreensão da "Questão Agrária"}

No Brasil, a preocupação com a agricultura e seu desenvolvimento foi uma questão constante ao longo do século XIX, especialmente na região central de Minas Gerais. Em um país essencialmente agrícola, o crescimento produtivo do setor agrário era uma das maiores 
preocupações para os agricultores e o Estado. Em um momento no qual as terras indicavam os primeiros sinais de desgaste, cujas as técnicas de produção eram caracterizadas como rudimentares, foram elaboradas propostas que visavam promover um novo modelo desenvolvimento no setor agrícola do país.

Angelo Alves Carrara no livro Estruturas agrárias e capitalismo (1999) e Maria Yedda Linhares no texto História Agrária $(1997 ; 2011)$ trazem abrdagens que retratam a sociedade rural no século $X X$, onde famílias utilizavam a agricultura para sustentar-se. A partir desses autores, pode-se dizer que tais famílias trouxeram consigo costumes, formas e técnicas de trabalho que foram registradas como memória para seus filhos.

Linhares (2011) aponta que foi no século XX, durante o processo inicial de expansão da agricultura, que o trabalho agrícola passou a agrupar homens e mulheres na mesma forma de trabalho. Em geral, para os agricultores o trabalho agrícola apresenta como principal atrativo a recompensa em se ter uma boa colheita, tendo assim uma maneira própria de viver (LINHARES, 2011). A crítica de Linhares é que essas questões que envolvem a relação do homem com a produção e a terra são incorporadas à história tardiamente.

Para Carrara (1999), o meio agrário não é pensado como um obstáculo para o desenvolvimento do capital, mas como uma grande motivação a esse processo. A autora volta o foco de suas pesquisas para os diferentes modos de produção e distribuição ligados à lavoura, reforçando no texto História Agrária (2011), que a "História Agrária" é a história de pessoas que vivem e lutam para trabalhar, criar os filhos, alimentar-se e descansarem ao fim de cada dia, buscando diferentes conhecimentos para auxiliar no desenvolvimento e transformação dos seus meios de subsistência.

Nesse sentido, Carrara (1999) estuda as transformações econômicas durante o período de transição dos modos de produção pré-capitalista para o capitalismo, concentrado as suas análises no interior da região central da Zona da Mata de Minas Gerais. Suas pesquisas foram realizadas espeficamente na área onde estão localizados atualmente os municípios de Ubá e de Visconde do Rio Branco. O autor também investigou outros municípios dessa região que se emanciparam entre as últimas décadas dos séculos XVIII e final do XIX. Cabe destacar que o povoamento dessa região foi movido pela descoberta do ouro no século XVIII, época em que todos buscavam Minas Gerais para gerar riquezas (CARRARA, 1999).

Na perspectiva de Carrara e Linhares, a agricultura se distingue em dois modelos de produção, a saber: o trabalho escravo e o camponês "assalariado", na medida que ocorria um avanço para a implantação do capitalismo. Assim, com a abolição da mão de obra escrava que no período colonial foi utilizada largamente pelos senhores donos de terras, especialemnte nos processos de cultivo e colheita de seus produtos, iniciava-se um novo 
modelo de vida denominado campesinato (CARRARA, 1999; LINHARES, 2011).

De acordo com Linhares (1997, p. 243), pode-se afirmar que:

\begin{abstract}
A história agrária, como e hoje conhecida, nasceu, nas primeiras décadas do século XX, de um encontro feliz com a geografia humana, tendo, de um lado, o historiador - preocupado em explicar as mudanças operadas pela ação do homem (os grupos sociais) através dos tempos - e, de outro, o geógrafo - dedicado ao estudo da relação do homem com o seu meio físico. Ao primeiro, pela própria natureza do campo de observação que lhe e especifico, cabe voltar-se sobre o passado em busca de informações e registros precisos, os mais abundantes possíveis, capazes de conduzir a uma explicação das sociedades humanas nas suas múltiplas determinações e complexidades. Já ao segundo cabe observar e descrever o presente a fim de detectar a ação do homem na ordenação do espaço que o envolve (o habitat).
\end{abstract}

Em um pimeiro momento, os historiadores pretendiam voltar suas atenções para uma área específica no campo, visando compreender a natureza e a sua apropriação pelo homem. Sendo assim, o termo "agrária" se distingue com base na compreensão do uso do solo em prol de se produzir algum tipo de agricultura (LINHARES, 1997).

Em um segundo momento, os pesquisadores tinham como objetivo descrever os processos de cultivos e cuidados com a terra do início ao fim, de modo a analisar a ação do homem e seu objeto de trabalho, bem como a organização do espaço que o envolve (habitat) (LINHARES, 2011). Sendo assim, conforme a autora, é possível dizer que as mudanças ocorriam no meio cultural e social, ou seja, no modo de viver da população. Desse modo,

Os motivos que levaram os historiadores a voltar suas atenções para a história regional, concebida como história econômica e social por excelência, prenderamse a duas ordens de razões. A primeira refere-se ao propósito de testar generalizações mais amplas através da utilização de dados de base, não agregados, que a visão ao microscópio, na expressão de Pierre Goubert, possibilita. A segunda decorre do fato de que a reconstituição de situações localizadas tem revelado a complexidade dos sistemas socioeconômicos, sendo, pois, fundamental à reformulação do conhecimento de uma "história geral" No Brasil, no entanto, essa tendência e muito recente, por motivos os mais diversos: desde a tradição de longa data ligada a "visão plantacionista" na formação da sociedade brasileira ate o seu extremo oposto representado pelas atuais tendências damicro-história, vulgarmente difundida como historia das mentalidades. (LINHARES, 2011, p. 160)

Por tais questões, aponta a hitoriadora, o tema história agrária demorou a fazer parte da linha de preocupações dos objetos de pesquisas. Ela resalva que, "no entanto, durante a maior parte dessa história - desse longo tempo decorrido -, foi a agricultura a atividade que congregou homens e mulheres, constituindo-se na principal fonte de vida e de trabalho" (LINHARES, 2011, p. 155). Surge, assim, a necessidade de se falar e retratar mais profundamente os processos que levaram ao desenvolvimento do setor agrário. 
Em resumo, a agricultura combina o trabalho, a terra e a tecnologia segundo condições sociais especificas. A analise histórica deve, pois, contemplar os elementos que se associam a fim de que seja possível uma explicação inteligível do processo histórico na agricultura, colocando-se no tocante aqueles fatores questões previas: o sistema socioeconômico em questao, as condicoes de acesso a terra, as normas jurídicas que regem a propriedade, o meio geográfico e as condições de uso da terra, o perfil demográfico, o universo profissional, as hierarquias sociais. Essa e a historia agrária de que falamos: a historia econômica e social do mundo rural. (LINHARES, 1997, p. 249-250)

Desta forma, essa perspectiva teorico-metodologica aponta que as diferrentes modalidades e meios de cultivos e plantios surgem como fatores positivos para 0 desenvolvimento econômico e social, o que influenciará o tipo de alimento plantado (arroz, café, feijão, milho, entre outros) de um país, região ou mesmo de uma determinada cidade. Nisso, cabe pontuar que independentemente de a produção ser de baixo ou alto porte, ambas modalidades colaboram para o crescimento de um devido lugar, gerando renda e trabalho (LINHARES, 2011).

Linhares (2011) faz uma análise dos séculos XVIII e XIX detendo-se à região do Rio de Janeiro e a sua ligação com Minas Gerais e Espírito Santo, estados que tinham desde então elos econômicos e demográficos importantes. No Brasil ainda predominava nesse período o trabalho escravo como sistema socioeconômico, especialmente nesses estados devido às grandes propriedades cafeeiras e as muitas áreas agrícolas voltadas para a produção de alimentos. Desses levantamentos e estudos, foi possível fazer algumas comparações entre municípios regiões e entender as estruturas fundiárias no século XIX, período em que se demarca a crise do escravismo e surge uma questão agrária (LINHARES, 2011).

Linhares (2011) aponta quatros municípios/regiões - Capivary (atual Silva Jardim) e Araruama, Valença e Campos, localizados no estado do Rio de Janeiro - que se diferenciavam naquele período por especificidades em suas estruturas fundiárias. A historiadora os classificou com base em suas dimensões, quantidade de produtos plantados por área, os tipos e variedade de produção, bem como o destino final da produção e onde se destacaram.

No tocante a estrutura fundiaria de quatro municipios/regiões, ressaltam-se dois modulos: (1) pequenas e medias propriedades ate 400, 480 e 500 hectares, respectivamente Capivary e Araruama, Valenca e Campos; (2) grandes propriedades, acima desses marcos regionais. Dos quatro municípios da amostra apenas Valenca, no medio Paraiba,vinculava-se ao sistema agroexportador (café); ja Campos, região canavieira por excelência, organizava-se no sistema da grande lavoura escravista, embora com producão destinada ao mercado interno; Capivary (atual Silva Jardim), localizada na periferia da plantation cafeeira, dedicava-se a uma modesta producão de subsistência destinada ao comercio local ou regional, na melhor das hipóteses; e, finalmente, Araruama, terra de passagem, destacouse por suas reservas florestais, de inicio, e pelo cultivode cana-de-acúcar, por uns tempos. (LINHARES, 1997, p. 256) 
Em 1970 desses quatros municípios, Valença se destacou por fazer parte do sistema agroexportador de café e Campos, por suas lavouras canavieiras destinadas ao mercado interno. No mesmo período, o município de Capivary possuía uma produção de subsistência destinada ao comércio local. Já Araruama, se destacou pelas suas reservas florestais, e pela produção de cana-de-açúcar por um breve período (LINHARES, 2011).

No entanto, é justamente Valença, o município exportador da amostra, aquele que apresenta a menor taxa de concentração da propriedade (área média, 901,82 ha, $53,68 \%$ da área total e $23,08 \%$ dos registros analisados). Enquanto isso, Campos tem o índice mais assustador de concentração fundiária, ou seja, apenas 22 registros, correspondendo a $1,12 \%$ do total da amostra, cobrem $44,70 \%$ da área total computada. Regiões de pequena lavoura, Capivary e Araruama, apresentam índices elevados de concentração, embora aí predominem pequenas e médias propriedades, com área média de 100 (Capivary) a 57 hectares (Araruama). O mesmo perfil se aplica, grosso modo, a Cantagalo ou a Juiz de Fora. (LINHARES, 2011, p. 164)

Vê-se que, embora alguns dos municípios citados dispunham de áreas de produção maiores do que de outros, isso não significa que esses se destacassem como principais produtores.O municío de Valença, por exemplo, que se enquadrava no sistema agroexportador (LINHARES, 2011), mas apresenta a menor taxa de concentração de propriedade. A região de Juiz de Fora, também, se encaixa a essa análise:

Em Juiz de Fora (MG), dos 101 proprietários de terras, cujos registros contêm dimensões das áreas possuídas, 79 controlam $25,7 \%$ da área total, enquanto 22 controlam $74,2 \%$ das terras. A análise de 91 inventários, para o período entre 1870 e 1929, confirma a tendência já identificada: 60 a 64\% da área agrícola são controladas por proprietários com mais de 1.000 hectares. (LINHARES, 2011, p.165)

Assim sendo, os dados confirmam a concentração do espaço social da propriedade decorrente ao período escravista, identificando que trabalhadores com ou sem recursos contribuíram para o desenvolvimento e ocupação do território. Como já mencionado, Minas Gerais foi um dos estados que mais utilizou trabalho escravo no trabalho agrícola, já os estados do Rio de Janeiro e Espírito Santo nem tanto, confirmando que nas áreas do interior de Minas Gerais, existiu um intenso trabalho escravo (LINHARES, 2011).

Assim, Linhares (1997) e Carrara (1999) entram em consonância em relação à produção de café ao indicar que essa foi inserida no Brasil ainda no período colonial, pontuando a importância dessa cultura para o desenvolvimento agrário desses estados.

\section{O povo e a terra na Zona da Mata Mineira}

No século XX, a busca pela mineração de ouro em Minas Gerais já não tinha o 
mesmo prestígio devido a baixa produção das lavras. Em razão disso, os grandes senhores de terras, munidos de mão de obra escrava, partiram para a agricultura. Antes da produção de café, eles se dedicaram principalmente ao cultivo da cana-de-açúcar que ainda apresentava certa lucratividade. Essas transformações na estrutura agrária acarretaram um crescente desenvolvimento populacional que precisou ser abastecido de gêneros alimentícios (com destaque para a lavoura de café e a criação de gado), bem como propiciou o desenvolvimento de diversificadas formas de agricultura (CARRARA, 1999).

À vista disso, o café torna-se o grande alicerce da economia da Zona da Mata Mineira, pois conforme Carrara (1999), a estrutura agrária desse período está associada ao produto que gera maior circulação de renda dentro de determinada região.

No entanto, conforme Paula (2006), não há como falar em Zona da Mata antes de 1870, pois o que impulsionou o desenvolvimento dessa região foi a chegada da linha ferroviária juntamente com a agricultura, que teve como principal fonte econômica a lavoura de café. Assim, a maior produtividade cafeeira da Zona da Mata se localizava nas áreas Norte e Leste, regiões com condições climátivas e solos propícias a esse tipo de cultura.

Radsack (2011) indica que desde o final do século XIX até meados do século XX a região da Zona da Mata Mineira passava por diversas transformações, como resultado do processo de ocupação e expansão de territórios. Pode-se, portanto, inferir que a região apresentava uma ligação estreita com a presença de mão de obra escrava e, consequentemente, ocorre o aumento populacional na região interligado a necessidade de produção agrícola de gêneros variados, mas com predominância na produção do setor cafeeiro como cultura agroexportadora.

A cidade de Espera Feliz foi contemplada devido às características geogáficas com um solo fértil e clima propício ao plantio das lavouras de café e, por conseguinte, com desenvolvimento das lavouras de exportação na região foi implantada uma linha fêrrea por onde esse produto podia circular, gerando a circulação de renda e alavancando a economia da região. Pode-se constatar que:

A produção cafeeira de exportação já consolidada nas ribeiras do Paraíba do Sul
começou a avançar a partir de 1850 para parte oeste e norte da área. Pode-se
assim caracterizar essa primeira área de Minas a produzir café em larga escala
como a sub-região onde se estabeleceram os maiores proprietários de terras. [...]
Vinte e três anos depois, as fazendas do café desses municípios estavam
consolidadas em enormes unidades de produção voltadas para a exportação, e
seus proprietários eram também os responsáveis pela construção da rede viária
necessária ao escoamento da produção até o porto do Rio de Janeiro.
(CARRARA, 1999,p.19-20)

Inicialmente a produção de exportação [café] tinha certa limitação que dificultava o escoamento do produto até o porto do Rio de Janeiro, porém no ano de 1870 essa dificuldade foi sanada pela a construção da linha férrea que ligava a região o Rio de Janeiro 
(CARRARA, 1999). Com isso, os produtores conseguiam o transporte necessário para o escoamento dos grãos até a região portuária. Nestes termos, a expansão mercantil da produção e de uma rede de transportes na região foi:

Consequência necessária do crescimento da produção cafeeira exclusivamente destinada ao mercado, a zona da Mata sul desde logo pôde contar com uma rede de transportes capaz de escoar esse produto: fosse a estrada do Couto (construída por Francisco Leite Ribeiro, ligando suas propriedades em Mar de Espanha ao porto do Rio de Janeiro), a União e Indústria, ou as estradas de ferro, cujos trilhos começaram a chegar na região sul nos 1870. (CARRARA, 1999, p. 27)

Naquele momento, a extinção da mão de obra escrava no conjunto das fortunas rurais não poderia deixar de provocar modificações importantes nos sistemas de trabalho. Em razão disso, já em 1872 acontece uma ocorrência de contrato de aluguel de serviços de escravos (no qual um proprietário busca serviços em seus territórios com escravos de outros donos de terra), em 1877 esse sistema de serviço passou a não existir, sendo assim, substituído pelo os arrendamentos de terras (CARRARA, 1999).

Nesse sentido, pode-se verificar que começavam a se tornar comuns contratos de "sociedade agrícola" entre proprietários rurais e também de formas de trabalho em transição para o capitalismo (CARRARA, 1999). Tal modelo produtivo buscava, portanto, maiores ganhos financeiros entre as partes.

Em 1872, foi registrada uma escritura de contrato social para o cultivo de uma fazenda de lavoura de que eram senhores e possuidores em partes iguais o major José Justiniano Carneiro (gerente), José Cesário de Faria Alvim e Antônio Cesário de Faria Alvim. (CARRARA, 1999, p. 83)

Desde aquela época, como se percebe, o café torna-se o meio de subsistência de muitas famílias, de modo que essa cultura é conhecida atualmente na região de Espera Feliz, como um produto de qualidade e destaque por seu cultivo e grandes exportações. De fato, o principal destaque no que tange à agrícultura foi (e continua sendo) a produção cafeeira. Nesse sentido, o café produzido na região é diferenciado quando comparado às demais localidades circunvizinhas.

Em termos técnicos, segundo especialistas, o grão produzido no município é de alta qualidade, sendo um dos melhores produzidos no Brasil.

A agricultura familiar é, muitas vezes, associada à pouca tecnologia e à baixa produtividade, mas uma família de pequenos produtores de cafés especiais prova que não é bem assim. Mais de 20 pessoas da família Lacerda vivem de uma pequena lavoura em Minas Gerais. Eles investiram em tecnologia e conhecimento e o resultado é um café de alta qualidade, com ótimo preço de mercado. A lavoura da família Lacerda fica na divisa de Minas Gerais com o Espírito Santo, entre os municípios de Espera Feliz e de Dores do Rio Preto. A região é conhecida pelo Parque Nacional do Caparaó, que abriga o Pico da Bandeira, com quase três mil 
metros de altura. É nesse cenário, bem ao lado do parque, que fica o sítio Forquilha do Rio, com 48 hectares, dos quais 21 plantados com café arábica. (GLOBO RURAL, 2017)

A citação acima se refere a uma propriedade rural localizada em Espera Feliz MG, que conseguiu produzir um dos melhores cafés da região, o "tipo especial". Segundo a família Lacerda, eles não se contentaram com o modo tradicional e cultural já existente, portanto buscaram aprimoramentos na produção para melhorar o seu produto.

De acordo com especialistas consultados pelo Globo Rural, o resultado disso é a qualidade, "a fama e também o ganho econômico". Sabe-se que os cafés especiais são vendidos com preços bem acima do mercado comum, ou seja, há uma valorização tanto no mercado nacional como internacional. Enquanto o valor da saca de $60 \mathrm{Kg}$ de café Arábica convencional é negociada na região (na época da veiculação da matéria) por cerca de $R \$$ 470,00 , o café do "Lacerda" alcança um preço médio de $\mathrm{R} \$ 1.500,00$ por saca (GLOBO RURAL, 2017).

Além disso, Espera Feliz apresenta importantes fatores geográficos que possibilitam melhores qualidades da produção cafeeira. Segundo os dados do IBGE (2018), algumas áreas do município estão localizadas a quase mil metros de altitude, já a sede municipal ocupa uma área que está a 748 metros de altitude, no sopé do Monte Feliz e da Serra do Bicudo. Verifica-se que o relevo apresenta bastantes serras, considerando que o município está situado no Maciço do Caparaó, região serrana do Brasil, localizada nas confluências do estado de MG e ES.

Nessa região predomina o clima tropical de altitude, típico em cidades de elevada altitude da região sudeste, onde predominam verões amenos e invernos frios, variando entre as médias máximas $25^{\circ} \mathrm{C}$ e médias mínimas de $12^{\circ} \mathrm{C}$.

O clima é subtropical a tropical, com duas estações bem definidas: a. Chuvas intensas e duradouras (Novembro até Abril) e b. a seca (resto do período). A pluviosidade anual varia em torno de $1600 \mathrm{~mm}$ e chega a $2200 \mathrm{~mm}$ em algumas zonas. A temperatura média é de cerca. 25두 chegam ao máximo nos meses de Dezembro - Janeiro atingindo até $400 \mathrm{C}$ e baixam nos períodos mais frios até $15^{\circ}$ C. Nas altitudes maiores chegam abaixo de 0 ㅇ $\mathrm{C}$ e no topo da Serra do Caparaó temperaturas abaixo de 0o C são comuns no inverno. (HORN e SOARES, 2007, p. 3)

Nisso, apesar de estar localizada em uma área montanhosa, Espera Feliz apresenta primavera e verão com temperaturas elevadas, já o outono e o inverno apresentam temperaturas próximas de $0^{\circ} \mathrm{C}$ e baixa umidade térmica. Essa característica de clima é muito favorável à cultura de café (IBGE, 2018). Tal fator aliado ao aprimoramento técnico agrícola favoreceu o desenvolvimento da produção cafeeira de alta qualidade, destacando algumas variedades conforme a Figura 1.

Os dados do IBGE (2018) revelam que o índice pluviométrico anual do município é 
de aproximadamente $1.595 \mathrm{~mm}$ e que, apesar de apresentar precipitações durante todo o ano, as chuvas estão mais concentradas no verão. Isso contribuiu para que a cultura do café passasse a prefigurar em Espera Feliz como principal fonte de renda a partir de meados do século passado.

O número 5 na Figura 1 indica as regiões Norte e Noroeste de Minas Gerais, áreas da localização geográfica da pequisa, onde predomina a produção de café da espécie Arábica. Essa espécie de café tem origem na Etiópia e foi adaptado às condições de clima e solo brasileiros, e se caracteriza por produzir cafés mais finos e requintados. No Brasil, os cafés dessa variedade são geralmente plantados em terrenos de altitudes superiores a 800 m, consideradas ideias para a produção de cafés de qualidade superior (BSCA, 2019).

Figura 1: Espécies de café na área Norte de Minas Gerais

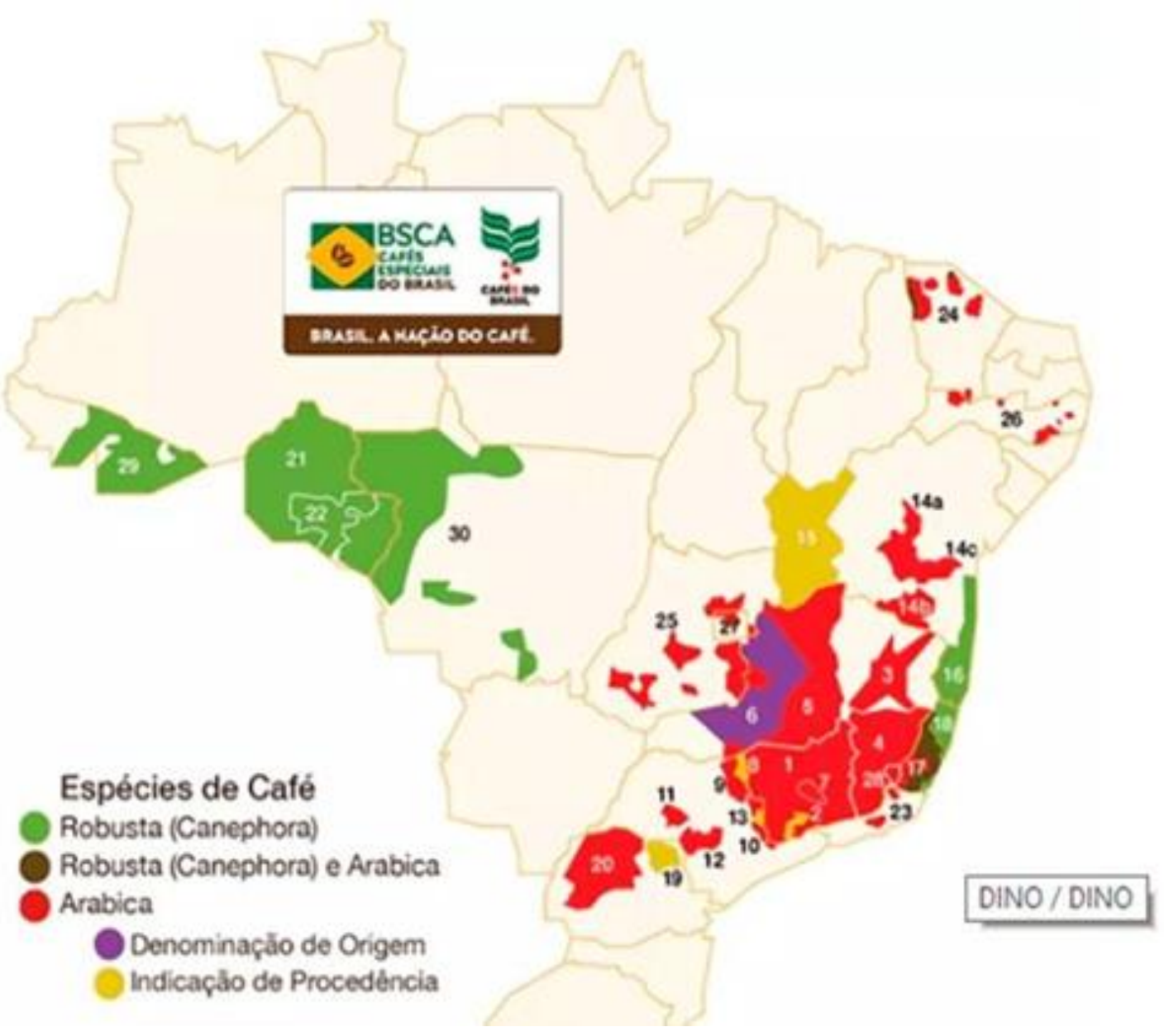

Fonte: BSCA (2019)

Diante do que foi discutido, busca-se na próxima seção identificar a produção dessa região de uma forma detalhada, entre os anos 1949 e 1950. 


\section{O desenvolvimento agrário de Espera Feliz}

Nesta seção será destacado o desenvolvimento agrícola em Espera Feliz na segunda metade do século XX, com destaque para a cafeicultura. A secão se desenvolverá, portanto, analisando como se deu o desenvolvimento agrícola do município, com base na análise dos dados do Censo Agrícola de Espera Feliz no ano de 1949-1950.

Tanto a agricultura como a cafeicultura possui uma história geopolítica e econômica no Brasil, tendo moldado as diversas formas de apropriação e uso do imenso patrimônio natural tropical e subtropical que formam o país. Em Espera Feliz a cultura cafeeira tem um grande impacto já apartir de fins do século XIX, especialmente por representar o trabalho do dia a dia, o sustento anual e, sobretudo, a economia local rural e urbana local.

Espera Feliz possui uma história com elementos importantes que envolvem desde a sua construção e emancipação política ocorrida em 1938. Tal processo histórico envolve fatores econômicos e políticos da época como, por exemplo, a chegada da Linha Férrea Leopoldina que ligou Espera Feliz aos estados do Espírito Santo (ES) e do Rio de Janeiro (RJ) no início do século XX. Um dos principais fatores que levou Espera Feliz a desenvolverse economicamente foi a chegada da linha de trem em 1910, interligado a cidades aos demais estados do Sudeste (SOUZA, 2008).

Todavia foi somente em 1913 que a estação ferroviária foi inaugurada, colaborando diretamente para o seu desenvolvimento econômico, político e administrativo. Conforme os registros do site Estações Ferroviárias do Brasil, a estação teria sido chamada entre 1911 e 1915 de Ligação, por ser um entroncamento. Uma vez que dessa estação saía o ramal Sul do Espírito Santo, ligando a cidade a Cachoeiro do Itapemirim, no Estado do Espírito Santo.

De acordo com o último censo do IBGE (2018), trabalham atualmente na área rural dessa cidade aproximadamente 8.422 pessoas. Este dado aponta que o trabalho no campo também é uma fonte importante para a economia local, considerando que o IBGE (2018) aponta que o município tem uma população estimada em 24.773 habitantes. Atualmente, o município continua a cultivar diversos tipos de alimentos como, por exemplo, a produção de milho, feijão, entre outros, porém a região se destaca pela demanda da produção de café de qualidade.

Nessa região, a correção do solo foi um avanço importante que permitiu o plantio em diferentes tipos de solo. Sendo assim, foi possível adaptar a cafeicultura em locais inadequados, com isso podemos dizer que este avanço sugerido pela adubação tem ajudado o produtor (IBGE, 2018). A figura 2 representa a correlação entre a área de produção de café e a quantidade em alqueires destinada por cada produtor à produção desse grão. $\mathrm{O}$ eixo $\mathbf{X}$ representa os respectivos produtores de café do período e o eixo $\mathbf{Y}$ representa a quantidade de alqueires produzidos. 
Figura 2: Produção de Café em Espera Feliz por Produtor, no período de 1949-1950.

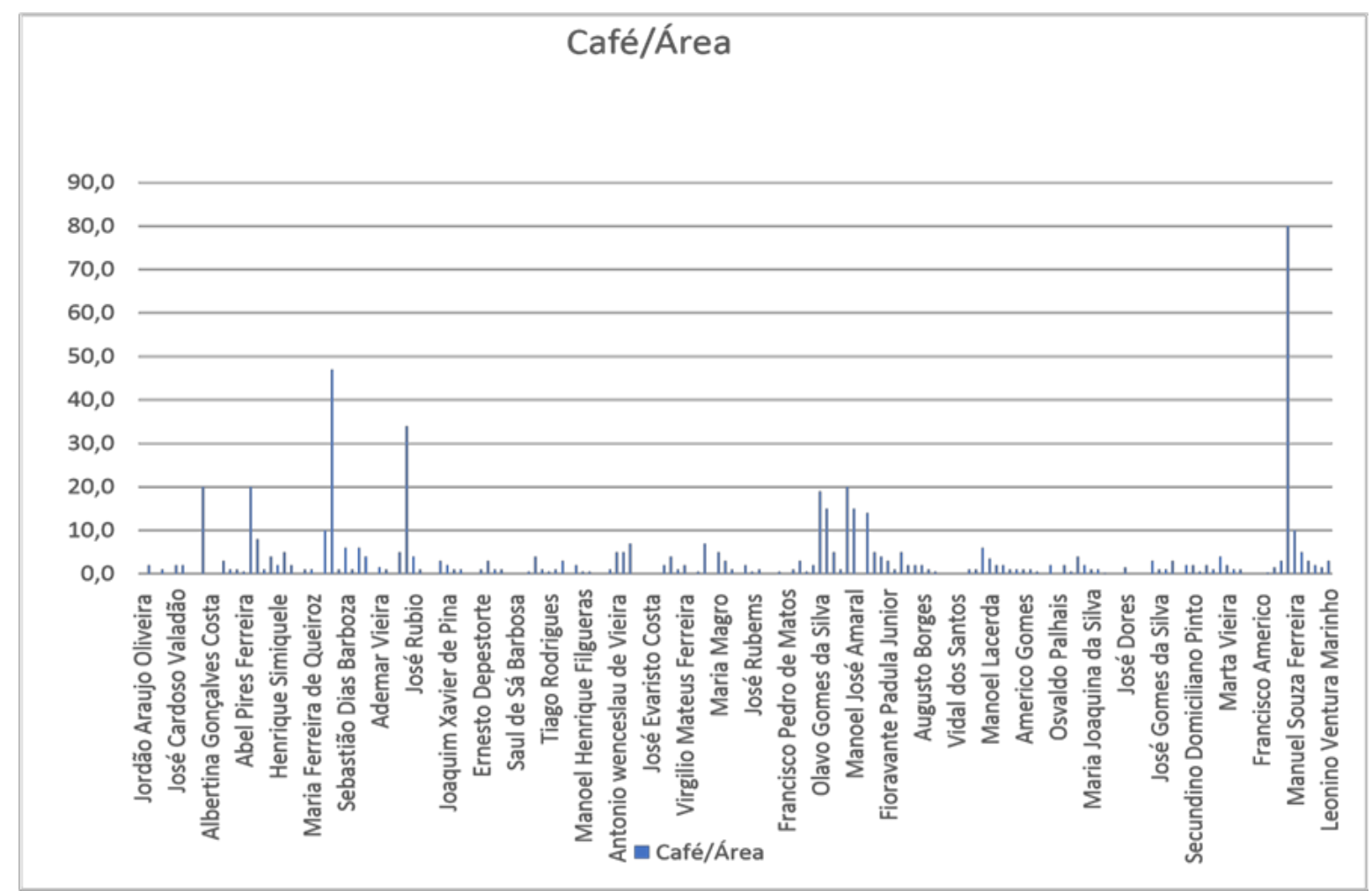

Fonte: Laguardia e Ferreira (2018)

Espera Feliz em 1950 contava com cerca de 242 produtores rurais que cultivavam em suas terras diversos tipos de plantações dividindo as suas atividades em produção dos quais 36 possuíam maior quantidade de terras. Pode-se analisar a quantidade de cada produto, a área em que foram produzidos, os maiores e menores produtores e a diversidade tais como café, feijão, milho, batata e arroz.

$\mathrm{Na}$ figura 2, está expressa as dimensões de cada área ocupada pelosmaiores produtores de café, sendo possível observar o número de agricultores que produzem em uma área menor e o número ou tamanho de quem produz em uma área maior. No entanto, o número total de agricultores identificado é de 110 produtores, que trabalham anualmente com a produção de café, sendo assim, se destaca como área total de produção no período, aproximadamente 515 alqueires.

Ao analisar a figura 2, pode-se observar que os produtores de pequenas áreas (com uma medida de 1/2 a 2 alqueires são: Amantina Alves de Souza, Celestino Dires Ferreira, Avelino Zanon, José Dainese, Maria Moreira, Ademar Vieira, Malvino Castro,Antonio Rubens, Francisco Inacio, Marta Vieira, Augusto Borges, Manoel Ratasio, Lourival Oliveira, Francisco Moreira Sampaio, José Gonçalves Borges, Claudino Nunes, Claudino Moreira Souza, Laurindo Ferreira, João Faria, Manoel Borges, Adão Marques Abreu, Waldemias Oliveira).

Por outro lado, há os que têm mais área em sua produtividade de café (com medida 
de 20 a 80 alqueires), que são: Roque Ferreira de Castro, Antonio Rubio Souza, Amelia de Freitas Moreira, José Grilo, Alvaro de Sá Barboza, Herminio Novais, Americo Vespeão de Carvalho. Tem-se, portanto, uma relação de menos produtores com números elevados de áreas para o cultivo do café. Na figura 3, será mostrado uma análise da produção de café por arrobas ( peso) dos maiores produtores de café na época em Espera Feliz, da qual representa a produção em quilos.

Figura 3: Produção de Café em Espera Feliz por Produtor, no período de 1949-1950.

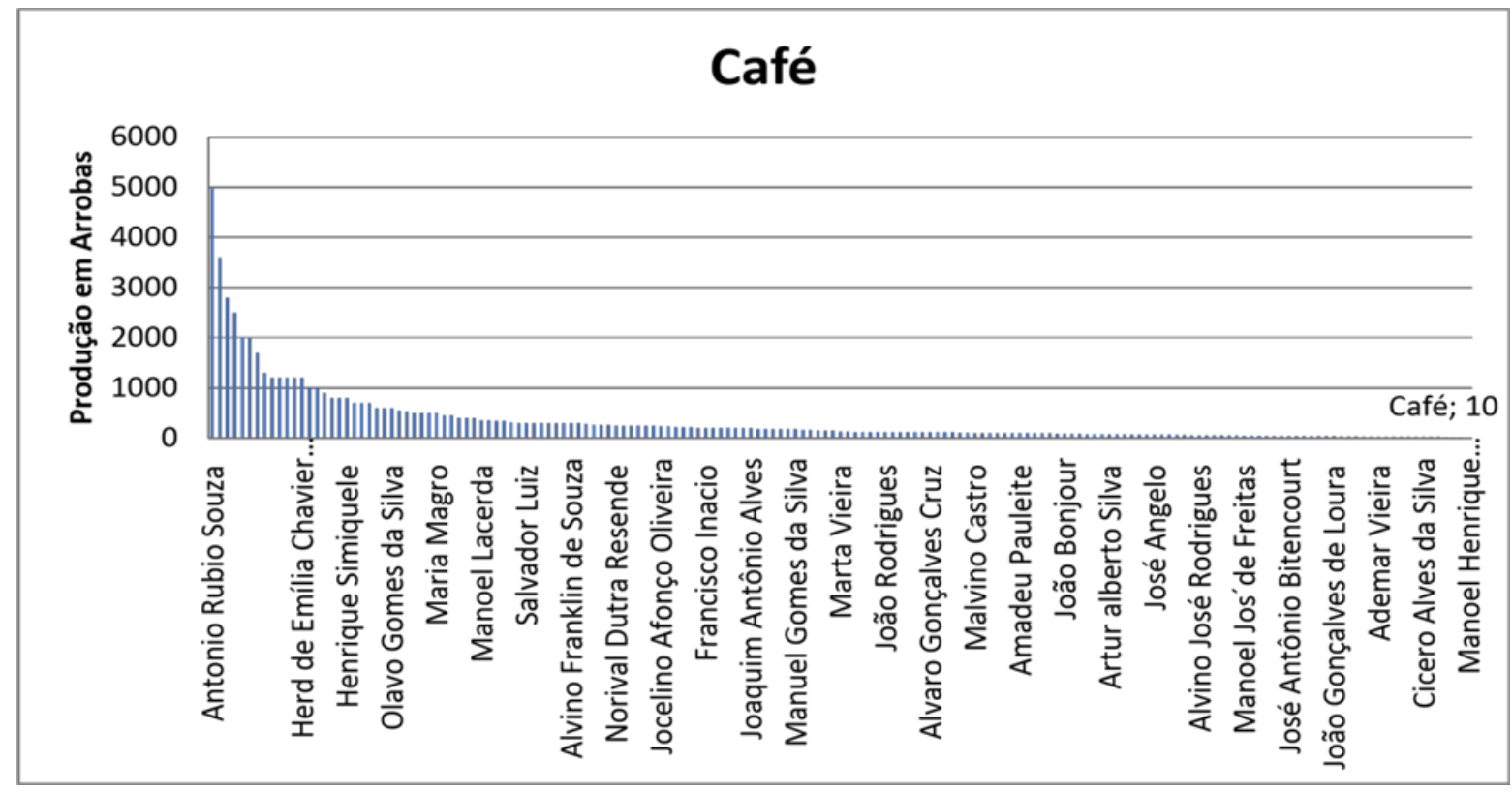

Fonte: Laguardia e Ferreira (2018)

No período analisado de 1949 -1950, apresenta 242 produtores em Espera Feliz, os quais 110 produziam café. Verifica-se, para o período, que o maior produtor de café é Antônio Rubens de Souza, confirmando uma produção de cerca de 5000 sacas e com a maior área destinada à produção de café. Assim, os produtores juntos fazem um montante de 16.965 sacas, onde a área média produzida é de 515 alqueires. Ainda, tem-se com mais de $50 \%$ da produção de café os seguintes produtores: Antonio Rubio Souza, Amélia de Freitas Moreira, Herd de Emília Xavier Rodrigues, Henrique Simiquele, Olavo Gomes da Silva, Maria Magro, Manoel Lacerado e Salvador Luiz.

Como se pode verificar, cerca de 21 produtores de café que apresentam menos de $50 \%$ da produção: Joaquim Donádio, Amantina Alves de Souza, Abel Pires Ferreira, Aparício Rodrigues Vieira, Celestino Dires, Ferreira, Virgílio Mateus Ferreira, Avelino Zanon, José Dainese, Maria Moreira, Ademar Vieira, Malvino Castro, Francisco Inácio, entre outros. Os dados indicam, como se percebe, que aparentemente não existe um equilíbrio na produção, pois muitos agricultores estão abaixo da média de $50 \%$, sendo uma minoria os 
produtores com maior produtividade e maiores extensões de terra na região. Isso indica a predominância de pequenas propriedades que se dedicavam à agricultura de subsistência.

Por fim, os dados analisados indicam que entre o período de 1949/1950, apesar de não se ter um número considerável de produtores de café na região, aqueles que se dedicavam a cultura tinham como principal renda esse produto. Esses produtores colaboravam com recursos para o crescimento da cidade e foram os principais empregadores de serviço local.

\section{Considerações Finais}

Esta pesquisa teve por finalidade tecer um resgate histórico da produção agrícola do município de Espera Feliz, remetendo-se ao século passado. Diante do exposto, constatouse que Espera Feliz apresentava, entre meados do século XX, como principal produto colaborador para a sustentabilidade local a exportação de café para os estados próximos (RJ e ES) e posteriomente para o mercado internacional, por se tratar de um tipo único de café (com diferentes variedades) produzido na região e valorizado no mercado.

Inicialmente a utilização das linhas férreas mostrou-se como um importante meio de transporte para a expansão agrícola do município, cujos trilhos cortavam a cidade entre os anos de 1910 a 1975 (época em que a linha foi desativada). Durante o seu período de funcionamento, a linha férrea contribuiu para o crescimento socioeconômico local por consistir no principal meio de transporte comercial da época na região, possibilitando a exportação das principais riquezas de Espera Feliz, bem como importando recursos para o crescimento da cidade, melhorando as estrutura e investimentos regionais.

A pesquisa aponta que, devido a garantia de serviço nas lavouras de café, Espera Feliz foi se desenvolvendo em três setores: econômico pois tinha um produto que garantia a circulação de capital na cidade; administrativo, pois na época somente pessoas muito influentes como fazendeiros entravam para o ramo politico; e social pelo, uma vez que no período as pessoas que se deslocavam em busca de trabalho acabavam se fixando próximos aos locais de trabalho, aumentado a população local. Por fim, pode-se concluir que, a economia de Espera Feliz partiu do cultivo do café, influenciando o crescimento socioeconômico regional, projetando o município como uma região rica em cafés de qualidade.

\section{REFERÊNCIAS}

BSCA. Associação Brasileira de Cafés Especiais Espécies de Cafés (Mapa). Disponível em: $<$ https://www.aquinoticias.com/2019/06/mapa-das-origens-produtoras-de-cafe-no-brasil-eatualizado/>. Acesso em: 10 de ago.2019.

BOENTE, Alfredo; BRAGA, Gláucia. Metodologia da pesquisa para a universidade. 
Editora: Brasport, 2004.

CARDOSO, Ciro Flamarion; VAINFAS, Ronaldo (orgs.) Dominios da história: ensaios de teoria e metodologia. 5a․ Ed.- Rio de Janeiro: Campus, 1997.

CARRARA, Angelo Alves. Estruturas agrárias e capitalismo: contribuição para o estudo da ocupação do solo e da transformação do trabalho na zona da mata mineira (séculos XVIII ...) Mariana: UFOP, 1999.

FRAGOSO, João; FLORENTINO, Manolo. História econômica. In. Domínios da história: ensaios de teoria e metodologia. Rio de Janeiro: Campus, 1997, p. 27- 43.

GLOBO RURAL. Família produtora de café consegue ótimos preços e produto de qualidade. Disponível em: http://g1.globo.com/economia/agronegocios/globorural/noticia/2017/08/familia-produtora-de-cafe-consegue-otimos-precos-e-produto-de-

qualidade.html>. Acesso em:18 de nov. 2019.

HORN, Adolf Heinrich; SOARES, Antônio Carlos P. Geologia da folha Espera Feliz SF. 24VA-IV.2007.

IBGE, Instituto Brasileiro de Geografia e Estatística 2018. Cendo Agrário. Disponível em: $<$ https://cidades.ibge.gov.br/>. Acesso em: 20 de Jan. 2019.

LAGUARDIA, Rafael Martins de O.; FERREIRA, Lendra de O. História Econômica: Agricultura da Zona da Mata Mineira. Projeto de Pesquisa. UEMG, 2018.

LINHARES, Maria Yedda. História agrária. In: Domínios da história: ensaios de teoria e metodologia. Rio de Janeiro: Campus. CARDOSO, Flamarion C.; VAINFAS, Ronaldo. (Orgs). Domínios da história: ensaios de teoria e metodologia. $2^{\underline{a}}$ ed. - Rio de Janeiro: Elsevier, 2011, p. 165-184.

. História agrária. In: Domínios da história: ensaios de teoria e metodologia. Rio de Janeiro: Campus. CARDOSO, Flamarion C.; VAINFAS, Ronaldo. (Orgs). 5a ed. - Rio de Janeiro: Editora Campus, 1997, p. 243-270. (versão eletrônica)

MARCONI, Marina de A.; LAKATOS, Eva M.. Técnicas de pesquisa (Vol. 2, pp. 35-36). São Paulo: Atlas, 2002.

PAULA, Ricardo Z. A. de. Região e Regionalização: um Estudo da formação Regional da Zona da Mata de Minas Gerais. Revista de História Econômica e Economia Regional Aplicada- vol. 1, no 1-Jul/Dez- $2006 . \quad$ Disponível em:<http://www.ufjf.br/heera/files/2009/11/artigo04.pdf>. Acesso em: 20 de mar. 2019.

RADSACK, Randolpho. Crime e justiça em períodos de transição. Termo de Santa Luzia do Carangola (MG), 1880-1892. In: XXVIII SIMPÓSIO NACIONAL DE HISTÓRIA.2015. Florianópolis. Anais eletrônicos. Florianópolis UFSC, 2015. Disponível em: <http://www.snh2015.anpuh.org/resources/anais/39/1434491078 ARQUIVO randolpho.pdf> . Acesso em: 10 de nov. 2019.

SOUZA, Adevaldo G. de. 1932 Complementação da História Político - Administrativo do Município de Espera Feliz(MG) - 1947-2008 Espera Feliz, 2008. 